University of Nebraska - Lincoln

DigitalCommons@University of Nebraska - Lincoln

$1-2003$

\title{
What Affects Influenza Vaccination Rates among Older Patients? An Analysis from Inner-city, Suburban, Rural, and Veterans Affairs Practices
}

\author{
Richard Kent Zimmerman \\ Tammy A. Santibanez \\ Janine E. Janosky \\ Michael J. Fine \\ Mahlon Raymund
}

See next page for additional authors

Follow this and additional works at: https://digitalcommons.unl.edu/publichealthresources

Part of the Public Health Commons

Zimmerman, Richard Kent; Santibanez, Tammy A.; Janosky, Janine E.; Fine, Michael J.; Raymund, Mahlon; Wilson, Stephen A.; Bardella, Inis Jane; Medsger, Anne R.; and Nowalk, Mary Patricia, "What Affects Influenza Vaccination Rates among Older Patients? An Analysis from Inner-city, Suburban, Rural, and Veterans Affairs Practices" (2003). Public Health Resources. 60.

https://digitalcommons.unl.edu/publichealthresources/60

This Article is brought to you for free and open access by the Public Health Resources at DigitalCommons@University of Nebraska - Lincoln. It has been accepted for inclusion in Public Health Resources by an authorized administrator of DigitalCommons@University of Nebraska - Lincoln. 


\section{Authors}

Richard Kent Zimmerman, Tammy A. Santibanez, Janine E. Janosky, Michael J. Fine, Mahlon Raymund, Stephen A. Wilson, Inis Jane Bardella, Anne R. Medsger, and Mary Patricia Nowalk 


\title{
What Affects Influenza Vaccination Rates among Older Patients? An Analysis from Inner-city, Suburban, Rural, and Veterans Affairs Practices
}

\author{
Richard Kent Zimmerman, MD, MPH, Tammy A. Santibanez, PhD, Janine E. Janosky, PhD, \\ Michael J. Fine, MD, MSc, Mahlon Raymund, PhD, Stephen A. Wilson, MD, \\ Inis Jane Bardella, MD, Anne R. Medsger, RN, MS, Mary Patricia Nowalk, PhD, RD
}

\begin{abstract}
BACKGROUND: Despite strong evidence of the effectiveness of influenza vaccination, immunization rates have reached a plateau that is below the 2010 national goals. Our objective was to identify facilitators of, and barriers to, vaccination in diverse groups of older patients.

METHODS: A survey was conducted in 2000 by computerassisted telephone interviewing of patients from inner-city health centers, Veterans Affairs (VA) outpatient clinics, rural practices, and suburban practices. The inclusion criteria were age $\geq 66$ years and an office visit after September 30, 1998.

RESULTS: Overall, 1007 (73\%) interviews were completed among 1383 patients. Influenza vaccination rates were $91 \%$ at VA clinics, $79 \%$ at rural practices, $79 \%$ at suburban practices, and $67 \%$ at inner-city health centers. There was substantial variability in vaccination rates among practices, except at the VA.
\end{abstract}

Nearly all persons who were vaccinated reported that their physicians recommended influenza vaccinations, compared with $63 \%$ of unvaccinated patients $(P<0.001)$. Thirty-eight percent of unvaccinated patients were concerned that they would get influenza from the vaccine, compared with only $6 \%$ of vaccinated persons $(P<0.001)$. Sixty-three percent of those vaccinated, in contrast with $22 \%$ of unvaccinated persons, thought that an unvaccinated person would probably contract influenza $(P<0.001)$.

CONCLUSION: Older patients need intentional messages from physicians that recommend vaccination. Furthermore, more patient education is needed to counter myths about adverse reactions. Am J Med. 2003;114:31-38.
$\mathrm{I}$ nfluenza causes about 20,000 deaths annually (1), with the elderly and those with chronic medical conditions at greatest risk. It is estimated that the influenza vaccine can prevent thousands of deaths annually, yet in 1999 , only $67 \%$ of elderly persons received the vaccine (2). Vaccination rates were even lower among elderly persons of Hispanic (58\%) and non-Hispanic black origin $(48 \%)$. Because of the burden of the disease and low immunization rates, the Healthy People 2010 goal for influenza immunization is $90 \%$, which includes reducing racial disparity in immunization rates. Achieving these goals, however, will be difficult without understanding what prevents the elderly from being vaccinated $(3,4)$.

From the Departments of Family Medicine and Clinical Epidemiology School of Medicine (RKZ, TAS, JEJ, MR, IJB, MPN), and the Department of Health Services Administration, Graduate School of Public Health (RKZ, ARM), University of Pittsburgh, Pittsburgh, Pennsylvania; the University of Pittsburgh Medical Center-St. Margaret Family Practice Residency (SAW), Pittsburgh, Pennsylvania; and the Division of General Internal Medicine, Veterans Affairs Pittsburgh Healthcare System, and the Veterans Affairs Center for the Study of Health Disparities (MJF), Pittsburgh, Pennsylvania.

Funded by HS09874 from the Agency for Healthcare Research and Quality, Rockville, Maryland.

Requests for reprints should be addressed to Richard Kent Zimmerman, MD, MPH, Department of Family Medicine and Clinical Epidemiology, University of Pittsburgh School of Medicine, 3518 Fifth Avenue, Pittsburgh, Pennsylvania 15261, or zimmer@pitt.edu.

Manuscript submitted March 7, 2002, and accepted in revised form August 16, 2002.
Previous studies have found several demographic, knowledge, and attitude factors to be associated with patient barriers to influenza vaccination. These factors include race (2), age (5,6), awareness ( 7 ), fear of side effects (7), efficacy concerns $(7,8)$, doctor recommendation (7), and fear that the vaccine causes influenza $(7,9)$.

The purpose of this study was to identify, in a diverse group of elderly patients, facilitators and barriers to influenza vaccination. We used the Triandis model, which includes facilitating conditions, habits, attitudes, social influences, and perceived consequences, for predicting health behaviors (10). We selected four types of practices to ensure access to a wide range of patients and vaccination policies: rural medical practices, suburban medical practices in a network of nonacademic practices affiliated with the University of Pittsburgh Medical Center in western and central Pennsylvania, outpatient clinics in Veterans Affairs (VA) health centers, and inner-city neighborhood health centers in Pittsburgh, Pennsylvania.

\section{METHODS}

\section{Subjects}

We selected patients using a two-stage, stratified, random cluster sampling method (11). In the rural and suburban strata, random samples of practices were selected. All inner-city and VA practices were selected because of small numbers. From each selected practice, all eligible physi- 
cians were included; eligibility criterion was having a practice consisting of $>50 \%$ primary care patients. This resulted in a sample of eight rural practices with 15 clinicians, nine suburban practices with 19 clinicians, three VA practices with 16 clinicians, and four inner-city practices with 15 clinicians. We then randomly selected elderly patients for each clinician using billing lists, with a target of 15 completed patient interviews per clinician. Patient inclusion criteria were age $\geq 66$ years, an office visit after September 30, 1998, and the ability to complete an interview independently in English or Spanish. Patients who were homeless, residing in nursing homes, or not currently living in the region, or who were deaf or had severe psychosis or dementia, were excluded. The study was approved by the Institutional Review Board of the University of Pittsburgh and by the Human Subjects Use Subcommittee of the Institutional Review Board of the VA Healthcare System of Pittsburgh.

\section{Questionnaire}

The questionnaire was based on the theory of reasoned action (12), specifically the Triandis model $(10,13)$ that includes facilitating conditions (ease of getting to a place for vaccination), habit (history of getting vaccinated), behavioral intention consisting of attitude about the activity (getting vaccinated is wise), social influences such as clinician influence on patients (doctor recommends immunization), and value of the consequences of the activity (immunization prevents influenza). The model predicts several health-related behaviors, including receipt of immunizations, exercise, and use of birth control, and has been used in different cultural and economic situations $(10,13-15)$. The Triandis model as used for influenza immunization is internally consistent and has been validated externally (10). A draft of the questionnaire was tested with elderly persons at a senior center and an urban residency clinic, and then revised. It contained approximately 86 questions, depending on skip patterns. Questions took several forms. Respondents were asked to indicate agreement/disagreement with statements, answer open-ended questions, and respond to lists of choices read by the interviewer. A codebook was developed to categorize responses to open-ended questions (16); similar responses were grouped and given a descriptive name. A $10 \%$ sample was recoded to test the validity of coding.

\section{Data Collection}

An introductory letter from the principal investigator and an endorsement letter from the patient's clinician were sent to each patient. Patients were offered a $\$ 20$ honorarium to complete the interview.

Computer-assisted telephone interviewing (CATI) was used, permitting direct data entry during the interview (17). The CATI system also managed the sample of persons to be contacted, directed question sequence, eliminated unintentionally skipped questions, and provided automatic range checks. Telephone interviews were conducted by trained personnel from April 17, 2000, to October 27, 2000, with the majority of interviews completed in the summer (11).

\section{Statistical Analysis}

We used SUDAAN software (RTI, Research Triangle, North Carolina), which is designed for the analysis of complex survey data. Analyses were weighted to account for the unequal patient selection probabilities. Weighted results are reported as percentages only, as unweighted numerators and denominators would not compute to reported percentages. Chi-squared tests were used to compare patients who did and did not receive the 1999-2000 influenza vaccine, and to compare responses by strata. Logistic regression analysis was performed to determine variables significantly associated with receipt of the influenza vaccine in the $1999-2000$ season. All variables with $P$ $<0.10$ in bivariate analyses were included with the outcome variable in a forward selection procedure. Analyses of open-ended items were unweighted and performed using SAS (SAS Inc, Cary, North Carolina), which utilizes the Pearson chi-squared statistic for tests of association. Statistical significance was set at $P \leq 0.05$.

\section{RESULTS}

We sent requests for participation to 1642 persons and found 259 to be ineligible or with invalid telephone numbers, leaving 1383 potential respondents. When we concluded interviewing, we had 1007 completed interviews (Table 1), 227 refusals, and 149 persons whom we were unable to contact, which yielded a response rate of $73 \%$.

Nine respondents reported not knowing their vaccination status and were excluded from analyses on vaccination status. Overall, 79\% $(\mathrm{n}=787)$ of respondents reported being vaccinated in the 1999-2000 season (Figure). There was substantial variability in influenza vaccination rates among practices for the three non-VA types of practices; $79 \%$ of respondents in both rural and suburban practices reported being vaccinated compared with $91 \%$ of VA patients and $67 \%$ of inner-city patients $(P=0.09)$. Immunization rates did not differ significantly by race ( $67 \%$ of blacks vs. $83 \%$ of whites, $P=0.15$ ). Among single/never married persons, $93 \%$ were vaccinated, compared with $84 \%$ of married, $80 \%$ of widowed, and $69 \%$ of separated/divorced persons $(P=0.01)$. Nearly every respondent who stated they were vaccinated said they planned to be vaccinated the next year (99\%), as compared with only $25 \%$ of those who were not vaccinated $(P<0.001)$.

Almost all respondents were aware of the recommendations that the elderly should receive yearly influenza vaccinations: $98 \%$ in rural, suburban, and VA centers, 
Table 1. Characteristics of Respondents by Type of Practice

\begin{tabular}{|c|c|c|c|c|c|c|}
\hline \multirow{2}{*}{ Characteristic } & $\begin{array}{c}\begin{array}{c}\text { Rural } \\
(\mathrm{n}=235)\end{array} \\
\end{array}$ & $\begin{array}{l}\text { Suburban } \\
(\mathrm{n}=298)\end{array}$ & $\begin{array}{c}\text { Veterans } \\
\text { Affairs } \\
(\mathrm{n}=254)\end{array}$ & $\begin{array}{l}\text { Inner-City } \\
(\mathrm{n}=220)\end{array}$ & \multirow[b]{2}{*}{$P$ Value } & \multirow{2}{*}{$\begin{array}{c}\text { Overall } \\
(\mathrm{n}=1007) \\
\text { Number }(\%)^{\star}\end{array}$} \\
\hline & \multicolumn{4}{|c|}{ Number $(\%)^{\star}$} & & \\
\hline Female sex $(n=1007)$ & $166(68)$ & $187(60)$ & $10(2)$ & $160(74)$ & 0.07 & $523(46)$ \\
\hline White race $(\mathrm{n}=1002)$ & $235(100)$ & $292(99)$ & $224(94)$ & $95(32)$ & 0.08 & $846(95)$ \\
\hline Lives alone $(\mathrm{n}=1003)$ & $88(33)$ & $106(37)$ & $70(25)$ & $115(52)$ & 0.07 & $379(33)$ \\
\hline \multicolumn{7}{|l|}{ Living with others } \\
\hline$\geq 1$ children in the household $(n=624)$ & $5(4)$ & $13(4)$ & $13(4)$ & $20(18)$ & 0.01 & $48(4)$ \\
\hline No. of adults in the household $(\mathrm{n}=624)$ & & & & & 0.21 & \\
\hline 2 & $125(88)$ & $150(76)$ & $146(80)$ & $70(68)$ & & $491(81)$ \\
\hline$\geq 3$ & $16(10)$ & $36(22)$ & $31(18)$ & $24(23)$ & & $107(17)$ \\
\hline Education $(\mathrm{n}=999)$ & & & & & 0.05 & \\
\hline Elementary school/some high school & $82(38)$ & $64(25)$ & $87(36)$ & $95(43)$ & & $328(33)$ \\
\hline High school/vocational/technical & $110(45)$ & $133(46)$ & $109(42)$ & $86(39)$ & & $438(44)$ \\
\hline Some college & $26(11)$ & $48(14)$ & $37(13)$ & $23(11)$ & & $134(13)$ \\
\hline College graduate & $16(6)$ & $50(15)$ & $17(9)$ & $16(7)$ & & $99(10)$ \\
\hline Marital status $(\mathrm{n}=1006)$ & & & & & $<0.0001$ & \\
\hline Never married & $3(1)$ & $13(5)$ & $12(3)$ & $25(10)$ & & $53(4)$ \\
\hline Married & $123(58)$ & $161(53)$ & $172(72)$ & $51(24)$ & & $507(59)$ \\
\hline Widowed & $95(37)$ & $113(39)$ & $39(15)$ & $100(46)$ & & $347(31)$ \\
\hline Divorced/separated & $14(4)$ & $11(3)$ & $30(10)$ & $44(20)$ & & $99(6)$ \\
\hline Has health insurance $(\mathrm{n}=1005)$ & $229(98)$ & $294(98)$ & $210(90)$ & $191(85)$ & 0.05 & $924(95)$ \\
\hline Household income $(\mathrm{n}=872)$ & & & & & 0.01 & \\
\hline$<\$ 10,000$ & $37(16)$ & $37(16)$ & $30(9)$ & $104(57)$ & & $208(16)$ \\
\hline$\$ 10,000$ to $\$ 19,999$ & $82(43)$ & $74(34)$ & $123(48)$ & $57(29)$ & & $336(41)$ \\
\hline$\$ 20,000$ to $\$ 39,999$ & $48(24)$ & $87(32)$ & $71(34)$ & $22(10)$ & & $228(29)$ \\
\hline$\geq \$ 40,000$ & $33(17)$ & $43(18)$ & $16(9)$ & $8(4)$ & & $100(14)$ \\
\hline Frequency patient sees doctor $(\mathrm{n}=1005)$ & & & & & 0.19 & \\
\hline Every 1 to 2 months & $25(10)$ & $26(7)$ & $38(15)$ & $49(24)$ & & $138(11)$ \\
\hline 3 to 4 times per year & $107(49)$ & $155(60)$ & $115(39)$ & $112(52)$ & & $489(50)$ \\
\hline$\leq 1$ time per year & $103(41)$ & $117(33)$ & $101(46)$ & $57(24)$ & & $378(39)$ \\
\hline
\end{tabular}

* All percentages are weighted and obtained using SUDAAN; the n's provided are unweighted.

and $94 \%$ in inner-city centers. The most frequently cited sources for this information were medical professionals (59\%), television (35\%), newspapers (27\%), magazines $(13 \%)$, radio $(11 \%)$, friends $(8 \%)$, and family $(8 \%$; more than one source could be cited; $n=964$ ). Among the 787 persons who were vaccinated, $98 \%$ were aware of the vaccine recommendations for the elderly, compared with $94 \%$ of those unvaccinated $(P=0.04)$.

Triandis model factors were examined by types of practice and by vaccination status. No clear patterns emerged from the comparisons of practices. Several factors of the model were significantly associated with vaccination status (Table 2). Among the facilitating conditions, over half of respondents who were unvaccinated, compared with $24 \%$ of those vaccinated, did not know that Medicare covered the cost of the vaccination $(P$ $<0.001)$. A large percentage $(94 \%)$ of those vaccinated were willing to receive the influenza and pneumococcal vaccine at the same visit as compared with only half
(51\%) of those unvaccinated $(P<0.001)$. However, almost all (97\%) subjects reported that it was easy to get to a place to be vaccinated.

Attitude, social influences, and perceived consequences of the activity also affected the decision to be vaccinated. Subjects who were vaccinated believed more frequently that getting vaccinated was a wise decision and thus were less likely to report that getting vaccinated was more trouble than it was worth (Table 2). Most respondents reported that their doctor and relatives or close friends believed that they should be vaccinated (Table 2). Subjects who were vaccinated were more likely than those who were unvaccinated to consider advice from friends and family members as important in affecting their decisions about their health. In assessments of perceived consequences, more than half (55\%) of all respondents thought that unvaccinated persons would probably contract influenza, whereas $69 \%$ thought that the influenza vaccine was efficacious (weighted data). Respondents 


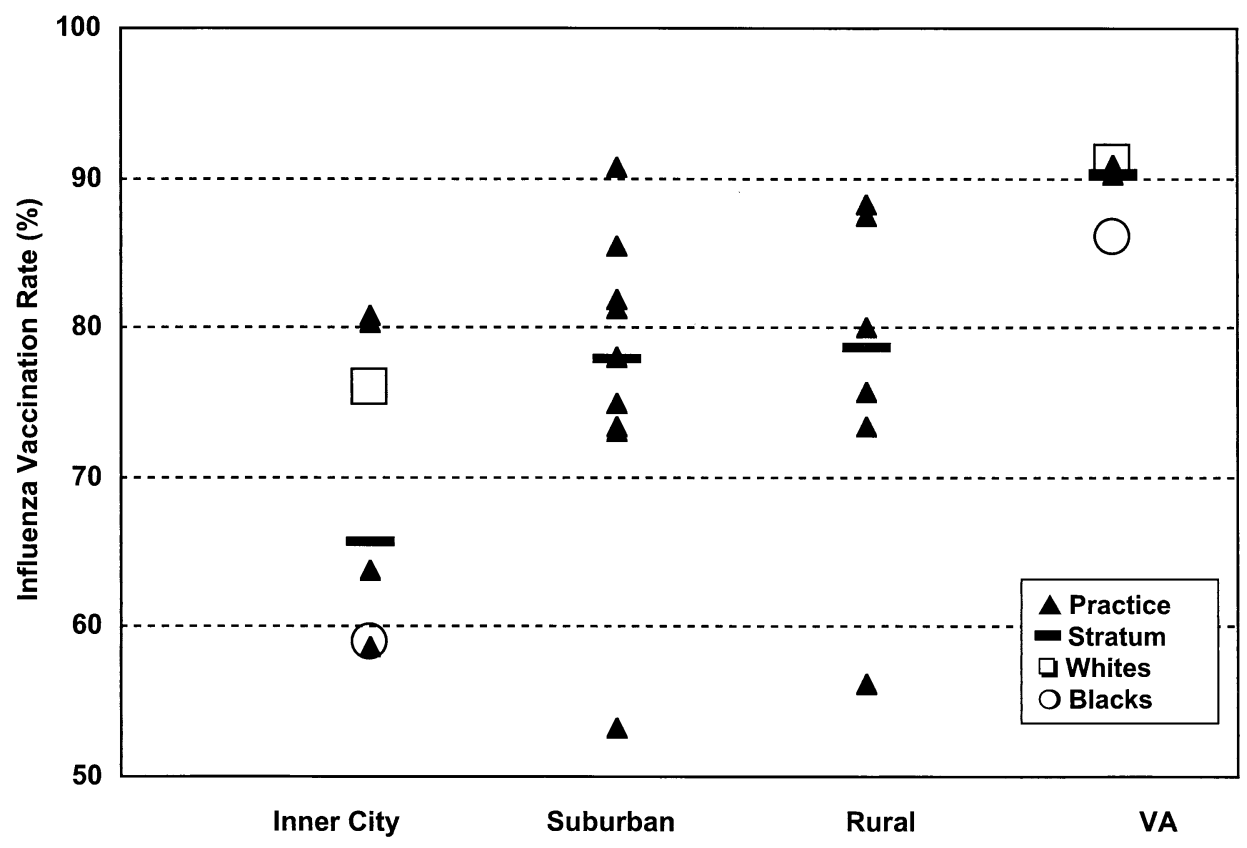

Figure. Variation in influenza vaccination rates, by strata, practice, and race. Individual practices are represented by triangles, and overall results within strata by bars. Rates by race are shown for the two strata with sizable numbers of blacks, but not for the two strata with few blacks. The number of practices within each stratum are four for inner-city, nine for suburban, eight for rural, and three for Veterans Affairs (VA).

who were vaccinated were more likely to believe that the vaccine was efficacious and that those unvaccinated would likely get influenza (Table 2).

In an open-ended question about what factors influenced the decision to get immunized, vaccinated persons gave the following reasons: the habit of being vaccinated $(24 \%)$, recommendation from their health care provider by mail or personally $(24 \%)$, the desire to avoid influenza (16\%), self/personal decision (14\%), having a high-risk factor such as heart disease or asthma (10\%), advice from family or friends (6\%), and the media (5\%).

Most respondents who were vaccinated did not have any concerns about the influenza vaccine (Table 3 ). The most common concern among those who were not vaccinated was getting influenza from the vaccine. Having a concern was associated with lower rates of vaccination (Table 3, $P<0.001$ ).

Subjects who were not vaccinated were read a list of 13 possible reasons for not being vaccinated (Table 4). The most commonly reported reasons were the belief that they were not likely to contract influenza, the belief that the vaccine causes influenza, concerns about side effects, and previous bad reactions to influenza vaccinations.

When we asked the 73 persons whose last vaccination was in or before 1997 why they had not had an influenza vaccination since then, the most common responses were side effects or getting influenza from the shot $(\mathrm{n}=46$ $[63 \%])$, no perceived need $(n=23[32 \%])$, and allergies $(\mathrm{n}=3[4 \%])$. Of the 93 respondents who never had an influenza vaccination, 17 (18\%) said they could be convinced to be vaccinated.

In logistic regression analyses, variables significantly associated with receipt of the influenza vaccine included type of practice, marital status, knowledge that Medicare covers vaccination cost, awareness of the recommendation that persons aged $\geq 65$ years should get influenza vaccinations every year, willingness to get both influenza and pneumonia vaccinations at the same doctor visit, belief that getting vaccinated is a wise thing to do, belief that their doctor recommends influenza vaccination, and belief that a person who does not get vaccinated will probably get influenza (Table 5). These variables accounted for $37 \%$ of the variance in influenza vaccination during the 1999-2000 season. Planning to get vaccinated next season was strongly associated with receipt of the vaccine (odds ratio $=138 ; 95 \%$ confidence interval: 67 to 285 ) when included in this analysis, whereas most other variables were no longer significant.

\section{DISCUSSION}

Nearly every elderly person who was vaccinated in the 1999-2000 season said that they planned to be vaccinated the next year, compared with only one quarter of those who were not vaccinated. We found that intention was 
Table 2. Beliefs about Influenza Disease and Vaccination, Social Influences, and Facilitating Conditions, by Influenza Vaccination Status*

\begin{tabular}{|c|c|c|c|}
\hline \multirow[b]{2}{*}{ Variable } & $\begin{array}{l}\text { Vaccinated } \\
(\mathrm{n}=787) \\
\end{array}$ & $\begin{array}{l}\text { Not Vaccinated } \\
\quad(\mathrm{n}=211) \\
\end{array}$ & \multirow[b]{2}{*}{$P$ Value } \\
\hline & \multicolumn{2}{|c|}{ Number $(\%)^{\dagger}$} & \\
\hline \multicolumn{4}{|l|}{ Facilitating conditions } \\
\hline $\begin{array}{l}\text { It is easy for me to get to a place where I can } \\
\text { get a flu shot }(\mathrm{n}=994)\end{array}$ & $761(97)$ & $195(96)$ & 0.31 \\
\hline $\begin{array}{l}\text { Do you think Medicare covers the cost of the } \\
\text { flu shot? }(\mathrm{n}=997)\end{array}$ & & & $<0.001$ \\
\hline Yes & $596(76)$ & $101(44)$ & \\
\hline No & $31(5)$ & $11(4)$ & \\
\hline Don't know & $159(19)$ & $99(52)$ & \\
\hline $\begin{array}{l}\text { Willing to get influenza and pneumococcal } \\
\text { vaccines simultaneously }(\mathrm{n}=954)\end{array}$ & $719(94)$ & $95(51)$ & $<0.001$ \\
\hline \multicolumn{4}{|l|}{ Attitudes } \\
\hline $\begin{array}{l}\text { I feel that getting a flu shot is a wise thing to } \\
\qquad \text { do }(n=968)\end{array}$ & $773(98)$ & $101(58)$ & $<0.001$ \\
\hline $\begin{array}{l}\text { I think that getting a flu shot is more trouble } \\
\text { than it is worth }(\mathrm{n}=969)\end{array}$ & $19(2)$ & $76(37)$ & $<0.001$ \\
\hline \multicolumn{4}{|l|}{ Social influences } \\
\hline $\begin{array}{l}\text { My doctor thinks that I should get the flu } \\
\text { shot }(\mathrm{n}=942)\end{array}$ & $753(98)$ & $115(63)$ & $<0.001$ \\
\hline $\begin{array}{l}\text { My relatives or close friends think that I } \\
\text { should get the flu shot }(n=841)\end{array}$ & $617(93)$ & $78(53)$ & $<0.001$ \\
\hline \multicolumn{4}{|l|}{ Perceived consequences } \\
\hline $\begin{array}{l}\text { The flu shot keeps a person from getting the } \\
\qquad \text { flu }(\mathrm{n}=959)\end{array}$ & $562(73)$ & $90(51)$ & $<0.001$ \\
\hline $\begin{array}{l}\text { A person who does not get the flu shot will } \\
\text { probably get the flu }(n=959)\end{array}$ & $493(63)$ & $53(22)$ & $<0.001$ \\
\hline
\end{tabular}

* Includes only patients who gave "Agree" and "Sometimes" responses and those whose vaccination status is known. Vaccination status for 9 respondents was unknown $(\mathrm{n}=998)$.

${ }^{\dagger}$ All percentages are weighted and obtained using SUDAAN; n's are unweighted.

Table 3. Perceived Consequences about Influenza Vaccine by Influenza Vaccination Status*

\begin{tabular}{|c|c|c|c|}
\hline \multirow[b]{2}{*}{ Response } & $\begin{array}{c}\text { Vaccinated } \\
(\mathrm{n}=787)\end{array}$ & $\begin{array}{l}\text { Unvaccinated } \\
(\mathrm{n}=211) \\
\end{array}$ & \multirow[b]{2}{*}{$P$ Value $^{\dagger}$} \\
\hline & \multicolumn{2}{|c|}{ Number (\%) } & \\
\hline No concerns & $697(89)$ & $60(28)$ & $<0.001$ \\
\hline $\begin{array}{l}\text { Concern that will get influenza from the } \\
\text { vaccine }\end{array}$ & $44(6)$ & $81(38)$ & $<0.001$ \\
\hline $\begin{array}{l}\text { Concern about side effects, such as local } \\
\text { reactions, or that vaccine will interfere } \\
\text { with other medications }\end{array}$ & $15(2)$ & $42(20)$ & $<0.001$ \\
\hline $\begin{array}{l}\text { Fear of needles, believes vaccinations are } \\
\text { unnecessary, and other miscellaneous } \\
\text { responses }\end{array}$ & $14(2)$ & $25(12)$ & $<0.001$ \\
\hline Reported allergy to vaccine & $5(1)$ & $11(5)$ & $<0.001$ \\
\hline Does not believe vaccine will prevent illness & $11(1)$ & $4(2)$ & 0.06 \\
\hline
\end{tabular}

* The question "What concerns, if any, do you have about the flu shot? was asked of all respondents whose vaccination status was known $(n=998)$. Vaccination status for 9 respondents was unknown. Up to three responses could be given by each person. Data are unweighted.

${ }^{\dagger}$ By chi-squared test. 
Table 4. Reasons Reported by Unvaccinated Persons for Not Being Vaccinated*

\begin{tabular}{|c|c|c|}
\hline \multirow[b]{2}{*}{ Triandis Model Factor } & \multirow[b]{2}{*}{ Reason } & $\begin{array}{l}\text { Respondents Giving Reason } \\
\qquad(\mathrm{n}=211)\end{array}$ \\
\hline & & Number $(\%)^{\dagger}$ \\
\hline \multirow[t]{5}{*}{ Facilitating conditions } & I didn't know I needed a flu shot $(\mathrm{n}=204)$ & $28(13)$ \\
\hline & $\begin{array}{l}\text { I had transportation problems getting to a } \\
\text { place where I could get a flu shot } \\
(\mathrm{n}=210)\end{array}$ & $6(5)$ \\
\hline & $\begin{array}{l}\text { I was sick when the flu shot was } \\
\text { recommended }(n=207)\end{array}$ & $12(4)$ \\
\hline & I did not have the time $(\mathrm{n}=208)$ & $10(3)$ \\
\hline & $\begin{array}{l}\text { I could not afford to get the flu shot } \\
\qquad(\mathrm{n}=210)\end{array}$ & $3(1)$ \\
\hline \multirow[t]{3}{*}{ Attitude } & $\begin{array}{l}\text { I don't think I'm likely to get the flu } \\
\quad(\mathrm{n}=190)\end{array}$ & $82(43)$ \\
\hline & $\begin{array}{l}\text { I don't feel a flu shot will prevent the flu } \\
(\mathrm{n}=179)\end{array}$ & $42(20)$ \\
\hline & I forgot to get it $(n=210)$ & $13(6)$ \\
\hline Social influences & $\begin{array}{l}\text { My doctor did not recommend a flu shot } \\
\quad(n=199)\end{array}$ & $52(21)$ \\
\hline \multirow{4}{*}{$\begin{array}{l}\text { Perceived } \\
\text { consequences }\end{array}$} & I think the flu shot causes flu $(n=192)$ & $78(41)$ \\
\hline & $\begin{array}{l}\text { I worry about side effects from the flu shot } \\
\quad(n=206)\end{array}$ & $70(32)$ \\
\hline & $\begin{array}{l}\text { I had a bad reaction to a flu shot in the past } \\
\qquad(\mathrm{n}=206)\end{array}$ & $51(28)$ \\
\hline & I dislike or fear needles or shots $(\mathrm{n}=209)$ & $18(8)$ \\
\hline
\end{tabular}

* Respondents answered "yes" or "no" to each of the listed reasons as they were read by the interviewer; thus, respondents could select more than one reason.

${ }^{\dagger}$ All percentages are weighted and obtained using SUDAAN; n's are unweighted.

Table 5. Variables Associated with the Receipt of Influenza Vaccine in the 1999-2000 Season in Logistic Regression Analyses

\begin{tabular}{lcc}
\hline \multicolumn{1}{l}{ Variable } & $\begin{array}{c}\text { Odds Ratio } \\
\text { (95\% Confidence Interval) })\end{array}$ & $P$ Value \\
\hline Strata & & \\
$\quad$ Veterans Affairs & $3.3(1.3-8.1)$ & 0.01 \\
Rural & $2.0(0.7-5.8)$ & 0.20 \\
Suburban & $1.4(0.5-3.7)$ & 0.54 \\
Inner-city & Referent & - \\
Marital status & & 0.001 \\
Single/never married & $9.2(2.9-29)$ & 0.01 \\
Married & $2.6(1.3-5.4)$ & 0.05 \\
Widowed & $2.0(1.0-3.9)$ & - \\
Separated/divorced & Referent & 0.002 \\
Do you think Medicare covers the cost of the flu shot? & & 0.06 \\
Yes & $3.3(1.6-6.7)$ & - \\
No & $3.0(1.0-9.3)$ & 0.02 \\
Don't know & Referent \\
Aware of recommendation to get the flu shot & $4.5(1.3-16)$ & 0.001 \\
Willing to get the flu and pneumonia shot at the same visit & $3.8(2.2-6.7)$ & $<0.001$ \\
Feel that getting the flu shot is wise & $13(6.2-26)$ & 0.001 \\
Belief that doctor thinks he/she should get the flu shot & $6.4(2.5-17)$ & 0.001 \\
Belief that if don't get vaccinated will probably get the flu & $3.7(2.2-6.3)$ & \\
\hline
\end{tabular}


the strongest predictor of behavior. Other key factors were knowledge of Medicare payment for the vaccine, belief that being vaccinated was a wise decision, belief in the vaccine's efficacy, and belief that others (especially one's doctor) recommended vaccination. Economics, access, and awareness of influenza vaccination recommendations were not important factors. Only $1 \%$ of those who were not vaccinated said that they could not afford the vaccination, and 5\% indicated transportation problems. In contrast with previous studies $(7,18,19)$, almost all patients were aware of the recommendations for vaccination against influenza. Thus, simply addressing access and awareness is unlikely to result in sufficiently increased rates to reach the 2010 national goals.

Perceived risk of contracting influenza was a predictor of vaccination status. Together, influenza and pneumonia are the fifth leading cause of death in the elderly in the United States, yet many patients do not realize that the disease is preventable by vaccination (20). This attitude may be due in part to the greater prevalence of, and therefore attention to, cardiovascular and neoplastic diseases.

The most common concerns cited by respondents who were not vaccinated were fear of contracting influenza from the vaccine and adverse effects. Previous studies have also reported that fear of adverse reactions $(5,7,8,21,22)$, concerns that vaccination may actually cause disease $(7,22)$, and fear of the pain from injection or needles $(7,8,19,21)$ lead many to decline vaccination. Lack of knowledge of the symptoms of influenza may lead to confusion about the efficacy of the vaccine; in another study, $44 \%$ of all respondents were not able to describe one or more of the classic symptoms of influenza (23).

The antivaccine movement may also contribute to the fear of adverse events. Although serious adverse events due to vaccination are rare and are limited to fever and mild, local reactions at the injection site (24), media attention to rare adverse events increases public awareness of their occurrence and may decrease receptivity to vaccination. We recommend that national education efforts be intensified to dispel the myths about alleged adverse events such as contracting influenza from the vaccine, and to address the burden of influenza.

Another key influence on patient behavior is physician recommendation, as more than one third of those not vaccinated in our study reported that their physicians did not recommend vaccination. Others have also found that recommendation by a health care provider was an important factor associated with vaccination (25), even among those with a negative attitude towards vaccination who were more likely to be vaccinated if their provider recommended it (25). Reminders such as postcards offer a way to inform patients about influenza vaccination and to deliver the message that their physician recommends im- munization (26), and are recommended strongly by the Task Force on Community Preventive Services $(27,28)$.

We observed a large variation in immunization rates for practices within strata, except for the VA, which may be due to differences in physician beliefs, in the use of interventions to raise rates, and office culture $(29,30)$. Thus, a "one-size-fits-all" intervention to raise rates may not be adopted universally, and a successful intervention may need to be tailored to reflect the unique set of resources, patient characteristics, and philosophies of each practice (30-33).

In this study, the VA had the highest immunization rates, with similar rates among blacks and whites, thus meeting the 2010 goals of $90 \%$. This may be explained by its use of a multimodal program to increase rates, including patient reminders, standing orders, freestanding vaccination clinics, and assessment of vaccination rates with feedback and incentives to clinicians $(34,35)$. For example, standing orders authorize nurses and pharmacists to administer vaccinations according to an institution- or physician-approved protocol without an individual order for each patient (36). The Task Force on Community Preventive Services strongly recommends provider reminders, standing orders, and assessment and feedback of performance $(27,28)$.

A possible limitation of this study is the use of selfreport of immunization status. Self-report is used in national surveys such as the Medicare Beneficiary Survey and the Behavioral Risk Factor Surveillance Survey. Compared with chart audit, self-report has a sensitivity of $92 \%$ to $100 \%$, a specificity of $71 \%$ to $98 \%$, and a $\kappa$ value of 0.72 to 0.92 (37-39). Although our study was limited to one state, immunization rates were similar to national rates. Finally, the outcome variable in our study, immunization status, is not a rare event; thus, the odds ratios overestimate the relative risk when they are greater than 1 (40).

We suggest three ways to inculcate the practice of regular influenza vaccinations among all older adults: clear and intentional recommendation by physicians to patients; implementation of multimodal interventions, such as standing orders to vaccinate by protocol; and patient education about disease risks and vaccine safety that are presented in culturally sensitive and literacy-levelappropriate forms. National educational efforts about the benefits of the vaccine, and the risks of influenza, should be intensified.

\section{ACKNOWLEDGMENT}

We thank Seymour Grufferman, MD, DrPH, for his advice and guidance on this project.

This paper was presented in part at the Distinguished Papers Session, Research Forum, Society of Teachers of Family Medicine Annual Meeting, San Francisco, April 27-May 1, 2002. 


\section{REFERENCES}

1. Centers for Disease Control and Prevention. Prevention and control of influenza: recommendations of the Advisory Committee on Immunization Practices (ACIP). MMWR Morb Mortal Wkly Rep. 2001;50:1-46.

2. Centers for Disease Control and Prevention. Influenza and pneumococcal vaccination levels among persons aged $\geq 65$ yearsUnited States, 1999. MMWR Morb Mortal Wkly Rep. 2001;50:532537.

3. Demicheli V, Jefferson T, Rivetti D, Deeks J. Prevention and early treatment of influenza in healthy adults. Vaccine. 2000;18:9571030.

4. Nichol KL, Margolis KL, Wuorenma J, Von Sternberg TL. The efficacy and cost effectiveness of vaccination against influenza among elderly persons living in the community. N Engl J Med. 1994;331: 778-784.

5. van Essen GA, Kuyvenhoven MM, de Melker RA. Why do healthy elderly people fail to comply with influenza vaccination? Age Ageing. 1997;26:275-279.

6. Petersen RL, Saag K, Wallace RB, Doebbeling BN. Influenza and pneumococcal vaccine receipt in older persons with chronic disease: a population-based study. Med Care. 1999;37:502-509.

7. Centers for Disease Control and Prevention. Reasons reported by Medicare beneficiaries for not receiving influenza and pneumococcal vaccinations-United States, 1996. MMWR Morb Mortal Wkly Rep. 1999;43:886-889.

8. Fiebach NH, Viscoli CM. Patient acceptance of influenza vaccination. Am J Med. 1991;91:393-400.

9. Nichol KL, Lofgren RP, Gapinski J. Influenza vaccination. Knowledge, attitudes, and behavior among high-risk outpatients. Arch Intern Med. 1992;152:106-110.

10. Montano DE. Predicting and understanding influenza vaccination behavior. Alternatives to the health belief model. Med Care. 1986; 24:438-453.

11. Zimmerman RK, Silverman M, Janosky JE, et al. A comprehensive investigation of barriers to adult immunization: a methods paper. $J$ Fam Pract. 2001;50:703.

12. Montano DE, Kasprzyk D, Taplin SH. The theory of reasoned action and the theory of planned behavior. In: Glanz K, Lewis FM, Rimer B, eds. Health Behavior and Health Education: Theory, Research, and Practice. San Francisco, California: Jossey-Bass Publishers; 1997:85-112.

13. Landis D, Triandis HC, Adamopoulos J. Habit and behavioral intentions as predictors of social behavior. J Soc Psychol. 1978;106: 227-237.

14. Davidson AR, Jaccard JJ, Triandis HC, et al. Cross-cultural model testing: toward a solution of the etic-emic dilemma. Int J Psychol. 1976;11:1-13.

15. Valois P, Desharnais R, Godin G. A comparison of the Fishbein and Ajzen and the Triandis attitudinal models for the prediction of exercise intention and behavior. J Behav Med. 1988;11:459-472.

16. Crabtree BF, Miller WL. Doing Qualitative Research. 3rd ed. Newbury Park, CA: Sage Publications; 1992.

17. Aday LA. Designing and Conducting Health Surveys. San Francisco: Jossey-Bass; 1989.

18. Hutchinson HL, Norma LA. Compliance with influenza immunization: a survey of high-risk patients at a family medicine clinic. J Am Board Fam Pract. 1995;8:448-451.

19. Nichol K, MacDonald R, Hauge M. Factors associated with influenza and pneumococcal vaccination behavior among high-risk adults. J Gen Intern Med. 1996;11:673-677.

20. National VAC. Adult Immunization: A Report by the National Vaccine Advisory Committee. Washington, DC: U.S. Department of Health and Human Services; 1994.
21. Gene J, Espinola A, Cabezas C, et al. Do knowledge and attitude about influenza and its immunization affect the likelihood of obtaining immunization? Fam Pract Res J. 1992;12:61-73.

22. Pregliasco F, Sodano L, Mensi C, et al. Influenza vaccination among the elderly in Italy. Bull World Health Organ. 1999;77:127-131.

23. Mieczkowski TA, Nowalk MP, Zimmerman RK, et al. Knowledge and beliefs about influenza, pneumococcal disease and immunizations among the elderly. J Am Geriatr Soc. 2002;50:1711-1716.

24. Margolis KL, Nichol KL, Poland GA, Pluhar RE. Frequency of adverse reactions to influenza vaccine in the elderly: a randomized, placebo-controlled trial. JAMA. 1990;307:988-990.

25. Centers for Disease Control and Prevention. Adult immunization: knowledge, attitudes, and practices—DeKalb and Fulton Counties, Georgia, 1988. MMWR Morb Mortal Wkly Rep. 1988;37:657-661.

26. Centers for Disease Control and Prevention. Recommendations of the Advisory Committee on Immunization Practices, the American Academy of Pediatrics, and the American Academy of Family Physicians: use of reminder and recall by vaccination providers to increase vaccination rates. MMWR Morb Mortal Wkly Rep. 1998; 47:715-717.

27. Centers for Disease Control and Prevention. Vaccine-preventable diseases: improving vaccination coverage in children, adolescents and adults. MMWR Morb Mortal Wkly Rep. 1999;48:1-15.

28. Gyorkos TW, Tannenbaum TN, Abrahamowicz M, et al. Evaluation of the effectiveness of immunization delivery methods. Can J Public Health-Revue Canadienne De Sante Publique. 1994; 85(suppl):S14-S30.

29. Miller WL, Crabtree BF, McDaniel R, Stange KC. Understanding change in primary care practice using complexity theory. J Fam Pract. 1998;46:369-376.

30. Crabtree BF, Miller WL, Aita VA, et al. Primary care practice organization and preventive services delivery: a qualitative analysis. $J$ Fam Pract. 1998;46:403-409.

31. Carney PA, Dietric AJ, Keller S, et al. Tools, teamwork, and tenacity: an office system for cancer prevention. J Fam Pract. 1992;35:388394.

32. McIlvain HE, Crabtree BF, Gilbert C, et al. Current trends in tobacco prevention and cessation in Nebraska physicians' offices. $J$ Fam Pract. 1997;44:193-202.

33. Greco PJ, Eisenberg JM. Changing physicians' practices. N Engl J Med. 1993;329:1271-1273.

34. Nichol KL. Long-term success with the national health objective for influenza vaccination: an institution-wide model. J Gen Intern Med. 1992;7:595-600.

35. Nichol KL. Improving influenza vaccination rates for high-risk inpatients. Am J Med. 1991;91:584-588.

36. Centers for Disease Control and Prevention. Use of standing orders programs to increase adult vaccination rates. MMWR Morb Mortal Wkly Rep. 2000;49:15-26.

37. MacDonald R, Baken L, Nelson A, Nichol KL. Validation of selfreport of influenza and pneumococcal vaccination status in elderly outpatients. Am J Prev Med. 1999;16:173-177.

38. Nichol KL, Korn JE, Baum, P. Estimation of outpatient risk characteristics and influenza vaccination status: validation of a self-administered questionnaire. Am J Prev Med. 1991;7:199-203.

39. Hutchison BG. Measurement of influenza vaccination status of the elderly by mailed questionnaire: response rate, validity, and cost. Can J Public Health—Revue Canadienne De Sante Publique. 1989; 80:271-275.

40. Zhang J, Yu KF. What's the relative risk? A method of correcting the odds ratio in cohort studies of common outcomes. JAMA. 1998; 280:1690-1691. 